\title{
An Interprofessional Learning Opportunity Regarding Pain and the Opioid Epidemic
}

\author{
Patricia Stoddard-Dare \\ Kelle K. DeBoth \\ Madalynn Wendland \\ Ryan Suder
}

\author{
Joan Niederriter \\ Rebecca Bowen \\ Sara Dugan \\ Miyuki Tedor
}

\begin{abstract}
An interprofessional response is needed to mitigate the deleterious effects of the opioid epidemic. Here we describe an interprofessional workshop for $n=307$ students from social work, pharmacy, medicine, nursing, occupational therapy, physical therapy, and speech-language pathology designed to help prepare professionals to work competently in interprofessional teams while serving clients impacted by substance misuse. A total of $n=201$ participants provided informed consent and completed a pre-and post-test electronic survey to measure the influence of the interprofessional workshop. Findings from a paired sample t-test reveal statistically significant differences at post-test regarding participant's self-described confidence 1) identifying their values and beliefs as they relate to substance misuse, 2) responding appropriately when interacting with someone with problematic substance use, 3) quickly finding local harm reduction resources, and 4) quickly finding local, available treatment resources for a person struggling with addiction. These findings suggest this educational curriculum is valuable in achieving its stated goals. Although future research is needed, findings from this study may be useful to health education systems across the country. This interprofessional education program can be emulated to aid in developing confidence in students and seasoned professionals in the healthcare workforce.
\end{abstract}

Keywords: Interprofessional education; opioid epidemic; substance use disorder; drughelp.care

The United States is in the midst of an opioid epidemic. A report from the Centers for Disease Control and Prevention (CDC, 2018) indicates that over 70,000 people lost their lives in 2017 due to drug overdose. Multiple factors are responsible for this epidemic, and sadly the healthcare system maintains some responsibility for this current situation. Leading up to the opioid epidemic, well-intentioned changes in the healthcare system contributed to an increase in opioid use disorders. Specifically, pain was conceptualized as the 5th vital sign (Phillips, 2000), and coordinated efforts at that time focused on reducing patient self-reported pain (Baker, 2017). Concurrently, the misconceived notion that prescription opioid medications were safe with a low potential for misuse and addiction proliferated (Van Zee, 2009). There was increased reliance on opioid medication rather than other approaches to address and manage patient pain (Fields, 2011), adding to the rise

Patricia Stoddard-Dare, MSW, PhD, Professor, School of Social Work; Kelle K. DeBoth, MOT, PhD, Assistant Professor, Health Sciences; Madalynn Wendland, DPT, Associate Professor, Health Sciences, Cleveland State University, Cleveland, OH. Ryan Suder, PhD, OTR/L, BCP, Clinical Manager, Cleveland Clinic Children's Hospital, Cleveland Clinic Lerner College of Medicine, Cleveland, OH. Joan Niederriter, MSN, PhD, Associate Professor, School of Nursing, Cleveland State University, Cleveland, OH. Rebecca Bowen, MA, CCC-SLP, Clinical Research Associate, The American Speech-LanguageHearing Association, Rockville, MD. Sara Dugan., Pharm. D., Associate Professor of Pharmacy, Northeast Ohio Medical University, Rootstown, OH. Miyuki Tedor, MA, PhD, Associate Professor, Department of Sociology, Cleveland State University, Cleveland, $\mathrm{OH}$. 
of physical dependence and subsequent opioid use disorders (Compton et al., 2016; Edlund et al., 2014). Most healthcare professionals are aware today that prescription opioids are highly addictive, and efforts have been taken to reduce reliance on prescription opioids to treat pain and to monitor use when they are indicated (Dowell et al., 2016).

Numerous systems are responsible for the opioid epidemic, and thus dedicated involvement of multiple systems is required to resolve the crisis. Reviews of the records of people who have experienced an opioid overdose suggest these individuals are likely to interact with at least one health professional in the six months preceding their overdose (Wagner et al., 2015). As such, all health professionals should be prepared to screen for problematic substance use and refer patients to assessment, treatment, and harm reduction resources. Additionally, health professionals should understand how pain plays into the initiation, continuation, and relapse of substance misuse. Finally, health professionals should form a solid understanding of the roles and responsibilities of interprofessional team members working together to address opioid misuse.

\section{Interprofessional Education}

Interprofessional collaborative practice (IPCP) is a concept previously referred to as "multidisciplinary care" or "interdisciplinary care." IPCP is characterized by healthcare professionals of diverse disciplines working together to make decisions regarding patients' health while applying their specific discipline's knowledge and skills (Bridges et al., 2011). Research indicates that IPCP is effective in stimulating collaborative care between healthcare professionals to improve the quality of care and outcomes for clients or patients (Schwindt et al., 2017). Interprofessional education (IPE) is defined by the World Health Organization (2010) as "students from two or more professions learning about, from and with each other to enable effective collaboration and improve health outcomes" (p. 7). Previous studies have indicated the potential for IPE to create positive attitudes toward future interprofessional work and collaboration, and to promote a reduction in clinical errors while improving the quality of team functioning, patient care, and patient outcomes (Sytsma et al., 2015; Wamsley et al., 2012). To aid entry-level healthcare professionals in learning the concepts of IPCP, exposing students to IPE is valuable.

Table 1. Accreditation Standards by Discipline

\begin{tabular}{l|l:l}
\hline Discipline & Accreditation Body & Accreditation Standard(s) \\
\hline Social Work & CSWE (2015) & Competency 1, 6, 7, 8 \\
Pharmacy & ACPE (2016) & Standard 11, Key Elements: 11.1, 11.2, \\
& & 11.3 \\
Medicine & LCME (2020) & Standard 6.4, 7.9 AOA 2014 \\
Nursing & ACEN (2019) & Standard 4.6 \\
Occupational Therapy & ACOTE (2013) & Standard B.5.21 \\
Physical Therapy & CAPTE (2016) & 6F, 6L3, 7D7, 7D12, 7D13, 7D34, 7D39 \\
Speech-Language Pathology & ASHA/CAA (2019) & Standard 1 (1.1, 1.2, 1.3) \\
\hline
\end{tabular}

Based on the collective experience, conventional wisdom, and culmination of learning about IPE of the current authors, the model for IPE should be developmental, integrated (including facilitation of practice-based experiences), and team-based. Health profession 
students are obliged to engage in IPE for programs to remain accredited (see Table 1 for Accreditation Standards by Discipline). Integrating IPE into health professional students' curriculum results in student gratitude towards social interactions with professionals from different disciplines, a desire to collaborate more often, and an enhanced understanding of the professional training of other professional disciplines (Sytsma et al., 2015).

\section{The Interprofessional Workshop}

A group of dedicated interprofessional faculty from two partnering Midwest Universities facilitated the workshop that is the focus of this paper. The group was comprised of at least one faculty member from social work, pharmacy, medicine, nursing, occupational therapy, physical therapy, and speech-language pathology. The group met for two hours per month to design interprofessional workshops, and the event described in this paper is one of the events this group developed and facilitated over a two-year period.

The workshop was tightly structured and took place in a conference hall with audiovisual equipment to display presentation content. A total of 307 students attended the event as part of a requirement for a course they were enrolled in at their respective departments. Based on information collected during event registration, participants were seated at a round table with approximately ten students representing various disciplines equally distributed among tables, and their tablemates became their interprofessional team members. A total of 28 interprofessional faculty members served as facilitators for one or two tables during the event.

The workshop began with a brief introduction ( 5 minutes) and two guest speakers - a police officer, and a person in recovery. The police officer described a local police-assisted addiction recovery program called Safe Passages, where police officers help facilitate entry into treatment rather than arrest for individuals struggling with substance misuse (20 minutes). This speaker helped students to think broadly about various professional's contributions, even unconventional and innovative contributions, in helping to address the opioid epidemic. The police officer provided the following innovative examples: 1) police paying out of their own pocket for a hotel for people struggling with addiction while they wait for a treatment center to open in the morning, 2) partnering with people in recovery they had come to know due to prior arrests, 3) police visiting local treatment centers to better learn about the facilities and the services provided, 4) transporting people struggling with addiction to treatment centers instead of jail, and 5) social workers joining police in emergency response teams to meet with individuals in their home shortly after an overdose to encourage them to seek treatment. The second speaker was a person in long term recovery from an opioid use disorder who shared her experiences of becoming addicted to physician-prescribed opioids for pain. She also shared her encounters and interactions with healthcare professionals over the years, which both helped and complicated her path toward sobriety at various moments in her journey (20 minutes).

The next component of the workshop was a brief overview of each profession's role in addressing the opioid epidemic (20 minutes). Students then heard from a guest speaker who specializes in pain management and shared information about the bio-psycho-socialspiritual manifestations of pain and various nonpharmacological approaches to address 
pain (20 minutes). Following a break (10 minutes), students were directed to their interprofessional teams. They were asked to reflect (5 minutes) on the question, "How do you see yourself in your future profession regarding these issues?"

Students were then introduced to drughelp.care, a website that helps treatment providers quickly find treatment and harm reduction resources for their patients (2 minutes). Subsequently, students were redirected to their interprofessional teams and were given a case study: a pregnant mother, named Pamala, with a substance misuse history who became physically dependent on opioids following a serious car accident and a subsequent 12-month Vicodin prescription that, once discontinued, developed into heroin misuse (8 minutes). A copy of the case study is available (DeBoth et al., 2019).

While reviewing the case study, the interprofessional teams worked through a series of prompts (35 minutes), such as, 1) Share with the group, your role in addressing Pamala's needs considering your profession. 2) Pharmacy students, speak about the most common opioids that are misused and what medications can be used to help treat opioid addiction. 3) Please share about the value of medication-assisted treatment for pregnant women with opioid use disorders. 4) For occupational therapy, speech-language pathology, and physical therapy, at what point or points in Pamala's timeline would your services be most beneficial for prevention and treatment? 5) Social work students, discuss what might be the most appropriate level of care for Pamala. 6) Utilize self-reflection to share something that stood out for you. The event ended with a ( 5 minute) wrap-up where the main points were reinforced. The next section describes each professions' role in addressing the opioid epidemic, methods to reduce pain, and a new web-based tool used during the event, drughelp.care.

\section{Profession's Role in Addressing the Opioid Epidemic}

Individuals struggling with substance misuse have unique bio-psycho-social-spiritual needs. Interprofessional health care workers provide patients with access to a wide variety of services and treatment options tailored to their specific needs. In the section below each profession's role pertaining to substance misuse treatment is described (see Table 2 for a summary). It is of value to note that professionals may have overlapping roles. An important contribution of interprofessional education is understanding the roles of various professions and learning to communicate and collaborate in an interprofessional team to advance patient well-being.

Social workers partner with individuals, groups, families, and communities to promote well-being and enact social change. The core values of social work include "service, social justice, dignity and worth of a person, importance of human relationships, integrity and competence" (National Association of Social Workers, 2017, p. 1). Social workers, advocate for people who are poor, vulnerable, or disenfranchised providing counseling and engaging in community organization, administration, policy advocacy, research, and education. 
Table 2. Roles of Interprofessional Team Members in Substance Misuse Treatment

\begin{tabular}{l|l}
\hline Profession & Role \\
\hline Social workers & $\begin{array}{l}\text { Prevention, screening, assessment, diagnosis, counseling, crisis } \\
\text { intervention } \\
\text { Assist in medication selection, dispense medication, dose } \\
\text { adjustment, monitor efficacy, adverse effect management } \\
\text { Pxaminacists } \\
\text { conditions, provide treatments and medical counseling, prescribe } \\
\text { medication } \\
\text { Assessment which includes physical exam and review of symptoms } \\
\text { and concerns; referral; education; provide treatments and } \\
\text { medications; advocacy } \\
\text { Prevent or adapt to injury, illness, or disability; help adapt } \\
\text { environments, conserve energy, and decrease pain; promote } \\
\text { engagement in meaningful life activities } \\
\text { Restore function and reduce reoccurrence of pain through exercise, } \\
\text { manual therapy, patient education, and stress management } \\
\text { Work with infants with neonatal abstinence syndrome on feeding } \\
\text { difficulties and later possible deficits in language and/or literacy; } \\
\text { Provide therapies to improve cognition, speech, language, and } \\
\text { swallowing for overdose survivors with brain injuries }\end{array}$ \\
\hline $\begin{array}{l}\text { Occupational therapists } \\
\text { (OTs) }\end{array}$ & $\begin{array}{l}\text { Physical therapists (PTs) } \\
\text { pathologists (SLPs) }\end{array}$ \\
\hline
\end{tabular}

Specific to problematic substance use, social workers provide school, community, and family-centered interventions aimed at prevention (Ramos et al., 2018). Social workers also play an integral role in the diagnosis and treatment of substance use disorders. Using a bio-psycho-social-spiritual approach, social workers provide screening and assessments to help identify the needs of clients who are struggling with substance misuse. Social workers serve as case managers, facilitate intake, develop treatment plans, provide psychoeducation, and facilitate individual, group, and family counseling for substance misuse and co-occurring mental health disorders. Social workers make referrals to and consult with other professional entities. For instance, social workers collaborate in interprofessional teams to determine the appropriate level of care for a client struggling with substance misuse based on a variety of factors including housing stability, interpersonal relationships, co-occurring mental and physical health conditions, and history of relapse. Finally, social workers have expertise in crisis intervention and help with crisis planning (American Society of Addiction Medicine [ASAM], 2020).

Pharmacists have expertise in optimizing patient-centered medication treatment outcomes that are safe and cost-effective. Pharmacists monitor and dispense medication and provide education. Part of their monitoring includes checking and updating the Prescription Drug Monitoring Program (PDMP). The PDMP is a state-wide prescription registry designed to track when, where, and who prescribes and fills certain prescription medications that have a high propensity for misuse. This information can be used to identify and intervene when misuse is suspected.

Palliative care and mental health pharmacists provide consultation, assist in medication selection, dose adjustment, monitoring of efficacy, adverse effect management, and medication regimen considerations such as drug interactions for pain or treatment of opioid 
use disorder. In an interprofessional team, pharmacists serve as experts on the use of medications in a treatment plan which is salient for a person at risk for, or struggling with an opioid use disorder. Some patients perform better in treatment when comorbid psychiatric conditions are treated with medication; therefore, consultation with a Psychiatrist is suggested for dually diagnosed clients.

Medication-assisted treatment (MAT) is a therapeutic approach that combines medication and counseling and is a best practice for treating opioid use disorders (National Institute on Drug Abuse [NIDA], 2016). Use of MAT may decrease the amount and frequency of illicit drug use, decrease crime and the spread of contagious disease, reduce cravings and the euphoric effects of a drug, and improve treatment retention (Substance Abuse and Mental Health Service Administration [SAMHSA], 2018). Interprofessional team members should be familiar with common medications that are used by patients struggling with opioid use disorders and pain such as Buprenorphine/Naloxone (Suboxone), Naltrexone (Vivitrol), Methadone, and Naloxone (Narcan) which should be routinely prescribed as part of a safety planning protocol to patients at risk of opioid overdose (NIDA, 2016).

Licensed physicians and other providers such as nurse practitioners and physicians assistants examine patients, complete a medical history, order tests, diagnose conditions, and provide treatments and medical counseling. Primary care providers, emergency room physicians, and psychiatrists are especially likely to interact with clients struggling with opioid use disorders. Medical doctors confirm an opioid use disorder diagnosis and help to diagnose and treat the patient's co-morbid medical conditions and physical dependency, which is essential in determining the appropriate level of care for the patient. Physicians review past medical history and test results to develop a treatment plan. Physicians carefully consider pain management strategies, weighing the need to reduce pain enough to minimize the risk of improper self-medication of pain with the risk inherent in opioid use.

Prescribers are urged to follow recommended guidelines for opioids to reduce the risk of misuse and increase positive patient outcomes (Dowell et al., 2016). Although it is considered an evidence-based intervention, MAT has been underutilized (Jones et al., 2015). To encourage and support physicians SAMHSA sponsors the Provider Clinical Support System (PCSS), which is an online portal that provides free training, mentoring, and other resources for DEA waivered providers to promote the use of medication-assisted treatment and best practices for patient pain management (PCSS, 2020).

In the traditional role of caregiver, nurses provide treatments and medications prescribed by state-authorized providers; assist the patient physically; gather health data and symptoms; and educate the patient and family members about their health and medications. Specific to substance use disorders, both social workers and nurses engage in assessment, referral, education and advocacy. A nurse's assessment of a patient includes a physical exam and a review of psychosocial concerns, familial history, and current and past drug use (Dahn, 2016). Like other members of the interprofessional team, nurses also provide education about the dangers of opioids and proper and responsible use of prescribed opioids, including disposal of unused medications (Waszak et al., 2018). Both 
social workers and nurses advocate for patients and for policies that support people impacted by opioid use disorders (Clark, 2014; Messer, 2017). Overall, nurses are a valuable part of the interprofessional healthcare team that implements evidence-based practices to address substance misuse in emergency, inpatient, and primary care settings (Agency for Healthcare Research and Quality, 2016; Korthuis et al., 2017).

Occupational therapists (OTs) work with people across the lifespan to improve health and wellbeing and to prevent or adapt successfully to live with injury, illness, or disability (American Occupational Therapist Association, 2014). Occupational therapists help patients at risk of becoming opioid dependent improve quality of life, coping, and selfmanagement skills by helping them engage in activities they need and want to perform (Chikwanha, 2019; Costa, 2016; Jedlicka et al., 2011; Rojo-Mota et al., 2017; Rowe \& Breeden, 2018). Since chronic pain is often a precursor to substance misuse, OTs use therapeutic modalities to help adapt environments, conserve energy, and decrease pain (Lagueux et al., 2018). OTs can also provide education on safe medication management, secure medication storage in the home, and signs to recognize substance misuse and overdose while also educating about the effects of substance use in daily life (McCombie $\&$ Stirling, 2018). Additionally, OTs can focus on improving engagement in meaningful life activities for those who have spent excessive time on substance use routines and patterns (Wasmuth et al., 2014). People struggling with substance spend a considerable amount of time trying to obtain and using drugs, OTs help those individuals repurpose their time to instead engage in meaningful activities.

Physical therapists (PTs), as movement specialists, work to optimize function for movement-related tasks (American Physical Therapy Association [APTA], 2018, 2019 2020). After a comprehensive examination, PTs implement a plan of care that includes various interventions such as aerobic training, strengthening exercises, manual therapy, functional training, adaptive equipment, posture/balance training, and patient education (APTA, 2009, 2018, 2020). PTs consult with an interprofessional team to maximize the clinical impact of services provided while working to enhance the quality of life of patients (APTA, 2018). A plan of care is selected for individuals with or at risk for opioid misuse to restore function and reduce reoccurrence of pain through exercise, manual therapy, education on healthy sleeping habits, and stress management (APTA, 2018; Fernández-deLas Peñas, 2015; Finan et al., 2013; Holth, 2008). By promoting a lifestyle that embraces regular exercise, PTs can help patients lessen the need for pharmacological alternatives (APTA, 2011, 2018).

Speech-language pathologists (SLPs) work with individuals across the lifespan to prevent, assess, diagnose, and treat deficits in communication (including speech, language, voice, and stuttering), social skills, cognition, and swallowing (American SpeechLanguage Hearing Association, 2019). SLPs assist individuals impacted by the opioid epidemic, serving both pediatric and adult populations. For example, SLPs work with infants suffering from neonatal abstinence syndrome (NAS) on feeding difficulties such as poor feeding efficiency, uncoordinated sucking, rejection of the nipple, cough, and reflux (Proctor-Williams, 2018). A portion of infants with NAS go on to experience developmental, behavioral, and educational challenges as children (e.g., deficits in language and/or literacy) and receive treatment from SLPs. In the adult population, SLPs 
work as part of an interprofessional team to treat patients who have an acquired brain injury. Anoxic and hypoxic brain injuries, common in individuals who have survived an opioid overdose, can result in devastating impairments in the areas of cognition, speech, language, and swallowing (Adams et al., 2019).

\section{Addressing Pain in Those at Risk or Struggling with Opioid Use Disorder}

Chronic pain management is a complex task best managed by an interprofessional team (Evans et al., 2016). Using a bio-psycho-social-spiritual approach helps deliver a wellrounded, individualized treatment for those patients who live with chronic pain and either have an opioid use disorder or are at risk for one (Eccleston et al., 2013). The interprofessional approach addresses the multiple needs of the individual with chronic pain including but not limited to physical and mental health, socialization, school or workrelated tasks, sleep hygiene, mindfulness, acceptance and coping, and leisure reintegration (Ali et al., 2017; Black \& Kashikar-Zuck, 2017; Cohen et al., 2017; Dysvik et al., 2010; Fisher et al., 2014; Hesse et al., 2015; Simons et al., 2010).

The interprofessional team's approach should focus on the engagement of the individual with chronic pain to activities that interest them, such as leisure or sport. The team can help by slowly reintegrating the patient into actions that are either modified or adapted to make them successful and achieve a feeling of accomplishment. Meanwhile, the treating team needs to focus on teaching mindfulness skills that help the patient better cope and/or accept the chronic pain and improve her ability to move forward in life with reduced reliance on, or cessation of opioids. Mindfulness activities can include yoga, guided meditation, and positive affirmations (Society, 2019).

The interprofessional team members need to recognize that failing to address or undertreating pain can lead to self-medicating and can be a barrier for achieving and maintaining abstinence from illicit drug use. Correspondingly, trauma, depression, anxiety, and poor sleep are pain facilitators that also need to be assessed and addressed by interprofessional team members (Harding et al., 2018). One overarching goal for all providers is to keep the substance-using patient engaged in treatment. One evidence-based approach, Motivational Interviewing, helps to evoke motivation for treatment and builds and supports a strong therapeutic relationship that improves treatment engagement and retention (Miller \& Rollnick, 1991; Providers Clinical Support System, 2017).

\section{Drughelp.care}

This interprofessional workshop introduced students to drughelp.care, an innovative and free website that allows substance misuse treatment provider agencies to easily register the number of treatment slots they have available on a daily basis. This website is fully searchable so it can be used by health professionals to find available treatment that matches an individual's characteristics and treatment needs. For example, website visitors can search for available treatment by level of care, type of insurance, dual diagnosis specialty, medication assisted treatments that are permitted, and specialty populations served such as pregnant women, minors, veterans, or transgender clients. Harm reduction resources are also included such as where to find Narcan, syringe exchange sites, fentanyl testing strips, and pregnancy prevention services. In 2018 drughelp.care debuted and was piloted in 
Northeast Ohio. Originally designed as a tool for professionals, due to the web application's success and Center for Disease Control and Prevention grant funding, drughelp.care will be expanded to include a user interface for those struggling with addiction and their friends and family members and has a goal of reaching other geographic areas. First responders have indicated drughelp.care improves their ability to quickly find available treatment that matches the treatment needs and personal characteristics of the person seeking treatment (VanAllen, 2018). Participants at the interprofessional workshop were shown a 3 minute video (Stoddard Dare, 2020) on how to navigate drughelp.care and were empowered to use this web tool to facilitate a warm handoff to available, compatible treatment for their patients who need substance misuse assessment or treatment. During the small group exercise portion of the workshop, in addition to considering their role, participants were asked to consider what treatment and harm reduction services the case study patient needed, and to use drughelp.care to search for available treatment.

\section{Purpose and Justification}

This interprofessional workshop was designed to help health professionals to understand their role in addressing the opioid epidemic and feel competent in working with patients struggling with substance misuse. The value of this specific interprofessional workshop curriculum was evaluated by measuring improvement in student's self-reported confidence in four domains: 1) identifying their values and beliefs as they relate to substance misuse, 2) responding appropriately when interacting with someone with a substance use disorder, 3) quickly finding local harm reduction resources, and 4) quickly finding local, available treatment resources for a person struggling with substance misuse.

Each of the four domains measured are salient in reducing opioid addiction and overdose death. First, facilitating examination of a professional's values and beliefs is important because it is through this process professionals can identify sources of bias and identify areas where stigma might inadvertently impede patient care. Second, some health professionals might not feel fully competent and confident responding appropriately when interacting with someone struggling with problematic substance use. Therefore, it is essential that all health professionals know and understand their role and responsibility when it comes to pain management and helping to prevent opioid use disorders or relapse. Third, harm reduction refers to a series of services and resources that can help to save the life of someone who is struggling with an active opioid use disorder or relapse. If every health professional was aware of local harm reduction resources and routinely connected those in need with these resources, overdose deaths and other comorbidities would decline (Hawk et al., 2015). Finally, oftentimes there is a small window of time when a person struggling with substance use disorder is amenable to treatment. For this reason, being able to quickly find local, available treatment resources for a person struggling with substance misuse is essential and life-saving. Taken together, this educational session and corresponding assessment of the outcomes are of importance.

\section{Method}

A nonprobability sample of $n=307$ students representing eight health professions (social work, occupational therapy, physical therapy, speech therapy, nursing, pharmacy, 
and medicine) was invited to participate in an online pretest survey. The survey examined their confidence in four domains, "identifying my own values and beliefs as they relate to substance misuse," "responding appropriately when interacting with someone with a substance use disorder," "quickly finding local harm reduction resources for a patient struggling with alcohol or drug addiction," and "quickly finding local, available substance misuse treatment resources for a pregnant woman struggling with addiction." A variable was created for each of the four domains, and they were measured on a five-point Likert scale $(1=$ strongly disagree to $5=$ strongly agree $)$.

Students were then invited to attend a two-and-a-half-hour interprofessional workshop and were then asked to complete an online posttest survey examining the same content. A total of 201 students completed and returned the consent forms and completed the pre and posttest surveys, and thus the analytic sample includes only those students.

Using the survey data, we aimed to assess the value of a specific interprofessional workshop curriculum in achieving statistically significant improvement in students' selfdescribed confidence regarding four substance misuse related areas. Data were analyzed to calculate the pre-test and post-test measures of student's confidence in four domains (values and beliefs, responding appropriately, quickly finding harm reduction resources, and quickly finding treatment resources) using a paired sample t-test.

\section{Results}

Of 307 students who attended the interprofessional workshop, a large number of them were from pharmacy $(n=80 ; 26.1 \%)$, nursing $(n=76 ; 24.8 \%)$, or occupational therapy $(n=45 ; 14.7 \%)$, and fewer students were from physical therapy $(n=39 ; 12.7 \%)$, speechlanguage pathology $(n=34 ; 11.1 \%)$, and social work $(n=33 ; 10.7 \%)$. Only students who signed the consent forms and completed both pre- and post-surveys were included in the analytic sample $(n=201)$. A high percentage of occupational therapy $(100 \%)$, physical therapy $(97.4 \%)$ and speech-language pathology $(94.1 \%)$ students from the original pool of attendees met this inclusion criteria. Fewer of the pharmacy (66.3\%), social work (39.4\%) and nursing (18.4\%) students completed all required documentation.

\section{Analysis and Results}

In the analytic sample, there was a statistically significant difference in pre-test $(M=4.21, S D=.720)$ and post-test $(M=4.41, S D=.560)$ scores for students who attended the interprofessional workshop regarding their self-described confidence identifying their values and beliefs as they relate to substance misuse $t(200)=-3.372, p=.001$. Further, there was a statistically significant difference in pre-test $(M=3.58, S D=.863)$ and post-test $(M=4.07, S D=.697)$ scores for students who attended the interprofessional workshop regarding their confidence in responding appropriately when interacting with someone with a substance use disorder and $t(200)=-8.057, p<.001$. Additionally, there was a statistically significant difference in pre-test $(M=3.30, S D=.954)$ and post-test $(M=4.27$, $\mathrm{SD}=.572$ ) scores for students who attended the interprofessional workshop regarding their self-described confidence quickly finding local harm reduction resources, $t(200)=-13.365$, $p<.001$. Finally, there was a statistically significant difference in pre-test $(M=3.07$, 
$S D=1.020)$ and post-test $(M=4.22, S D=.634)$ scores for students who attended the interprofessional workshop regarding their self-described confidence quickly finding local, available substance misuse treatment resources for a person struggling with addiction, $t(200)=-14.316, p<.001$.

Table 3. Comparison of confidence pre and post workshop $(n=201)$

\begin{tabular}{|c|c|c|c|}
\hline \multirow[b]{2}{*}{ Confidence in.. } & \multicolumn{2}{|c|}{ Mean (SD) } & \multirow[b]{2}{*}{$t$} \\
\hline & Pre & Post & \\
\hline Values and beliefs & $4.21(0.72)$ & $4.41(0.56)$ & $-3.372 *$ \\
\hline Responding appropriately & $3.58(0.86)$ & $4.07(0.70)$ & $-8.057 * *$ \\
\hline Finding local harm reduction resources & $3.30(0.95)$ & $4.27(0.57)$ & $-13.365 * *$ \\
\hline $\begin{array}{l}\text { Quickly finding local, available } \\
\text { substance misuse treatment resources }\end{array}$ & $3.07(1.02)$ & $4.22(0.63)$ & $-14.316^{* *}$ \\
\hline
\end{tabular}

${ }^{*} p=.001,{ }^{* *} p<.001$

\section{Discussion}

This paper described a workshop that builds on a call for interprofessional education focused on opioids (Kaufman, 2019) and helps to extend the emerging literature regarding empirically evaluated opioid-specific interprofessional education opportunities (Brooks et al., 2017; Fusco et al., 2019; Hager et al., 2018; Monteiro et al., 2017). We find statistically significant increases in all four outcome variables measured among students who attended a two-and-a-half-hour interprofessional workshop.

Aside from statistical significance, the practical significance of these findings also needs to be considered. Of importance, we observe students moving from a neutral rating of their confidence to a category of agreement for three of the four variables measured. Specifically, for questions about their confidence in their ability to respond appropriately, we observe an increase from 3.58 (neutral) to 4.07 (agree). Similarly, we observe an increase from 3.30 (neutral) to 4.27 (agree) for confidence to quickly locate harm reduction resources, and from 3.07 (neutral) to 4.22 (agree) for confidence in quickly finding locally available treatment resources. On a practical level, the ability to increase students' levels of confidence in a short two-and-a-half-hour educational session is encouraging.

One unique facet of this workshop, the use of drughelp.care, merits further consideration. Successful replication of these outcomes would no doubt be increased by a community's effort to encourage registration of local treatment and harm reduction resources with drughelp.care prior to a workshop. Efforts to promote community registration with drughelp.care can be led by local drug and mental health boards, universities, treatment provider agencies, Medicaid providers, laypersons, or members of any profession mentioned here. 


\section{Limitations}

This study is not without limitations. First, it relies on the participant's self-reported perceptions of their confidence. These perceptions may be subject to a social desirability bias and may not correspond to actual changes in behavior. Additionally, confidence was measured on a five-point Likert scale which limits variability, and qualitative comments were not collected. An additional limitation is uneven participation in the study component of this event by students from various disciplines. Future research should use a uniform procedure within all participating disciplines to solicit informed consent from all students who participate in this workshop. Finally, this research relies on a nonexperimental design, and a randomized experimental design is always preferred.

\section{Implications for Practice}

While the overall value of interprofessional education has already been established, we find that an interprofessional education event can increase student's confidence to understand their values and beliefs, respond appropriately, and find treatment and harm reduction resources in a timely way for patients struggling with opioid use disorders. Given the broad scope of the problem and the grave outcomes of opioid use disorder when left untreated, it makes sense to support interprofessional education efforts like the learning opportunity described here. Universities could consider adding a similar interprofessional education event to their curriculum focusing on both opioids and other substance use disorders. Beyond college students, healthcare leaders such as healthcare institutions and community health boards could consider hosting a workshop like the one described here for existing licensed professionals. Finally, an interinstitutional summit that brings together students and professionals could be valuable to share lessons learned and exchange ideas.

\section{Implications for Policy}

Although further research is needed, our findings reinforce the value of interprofessional educational experiences to help address the opioid epidemic. Professional bodies such as the CSWE have codified interprofessional skills as an essential component of professional competency. Given the apparent value of interprofessional workshops such as the one discussed here, universities and health institutions could consider organizational policy and structural changes necessary to facilitate the logistical execution of interprofessional education events such as designated funding, finding a common meeting time, and awarding workload credit to staff that plan and facilitate these events. Funding opportunities that could help to fund these workshops are emerging throughout the country as the federal and state governments search to curb the opioid epidemic (NIDA, 2019).

\section{Implications for Research}

Following the lead of others who have published in this emerging area, future research should include additional indirect measures as well as direct measures of student's increase in knowledge (Monteiro et al., 2017) and their subsequent changes in practice behaviors. 


\section{Conclusion}

To address the opioid crisis, we aimed to assess the value of an interprofessional workshop curriculum in improving student's readiness to intervene with patients struggling with opioid misuse. Our findings suggest this educational curriculum is valuable in achieving its stated goals. Specifically, we find statistically significant improvement in students self-described confidence identifying their values and beliefs as they relate to substance misuse, responding appropriately when interacting with someone with a substance use disorder, quickly finding local harm reduction resources, and quickly finding local, available substance misuse treatment resources for a person struggling with opioid use disorder. Findings from this study are useful to health education systems across the country as they consider curricula to promote interprofessional education specific to opioid use disorder. This interprofessional education program can be emulated to develop competency in students and seasoned professionals in the healthcare workforce.

\section{References}

Accreditation Council for Occupational Therapy Education. (2013). 2011 Accreditation council for occupational therapy education (ACOTE®) standards and interpretive guide. https://www.aota.org//media/Corporate/Files/EducationCareers/Accredit/Standards/2011-Standards-andInterpretive-Guide.pdf

Accreditation Commission for Education in Nursing. (2019). ACEN accreditation manual - 2017 standards and criteria [Updated 2019].

https://www.acenursing.org/for-programs/general-resources/resources-acenaccreditation-manual/

Accreditation Council for Pharmacy Education. (2016). Accreditation standards and guidelines for the professional program in pharmacy leading to the Doctor of Pharmacy degree. https://www.acpe-accredit.org/pdf/Standards2016FINAL.pdf

Adams, R., Corrigan, J., \& Dams-O'Connor, K. (2019). Opioid use among individuals with Traumatic Brain Injury: A perfect storm. Journal of Neurotrauma, 37(1), 211216. https://doi.org/10.1089/neu.2019.6451

Agency for Healthcare Research and Quality [AHRQ]. (2016). Medication assisted treatment models of care for opioid use disorder in primary care settings [Technical Brief Number 28]. https://effectivehealthcare.ahrq.gov/sites/default/files/pdf/opioiduse-disorder_technical-brief.pdf

Ali, A., Weiss, T. R., Dutton, A., McKee, D., Jones, K. D., Kashikar-Zuck, S., Silverman, W. K., \& Shapiro, E. D. (2017). Mindfulness-based stress reduction for adolescents with functional somatic syndromes: A pilot cohort study. Journal of Pediatrics, 183, 184-190. https://doi.org/10.1016/j.jpeds.2016.12.053

American Occupational Therapist Association [AOTA]. (2014). Occupational therapy practice framework: Domain and process (3rd ed.). American Journal of Occupational Therapy, 68, S1-S48. https://doi.org/10.5014/ajot.2014.682005 
American Physical Therapy Association [APTA]. (2009). Minimum required skills of physical therapist graduates at entry-level.

https://www.apta.org/uploadedFiles/APTAorg/About_Us/Policies/BOD/Education/M inReqSkillsPTGrad.pdf

APTA. (2011). Today's physical therapist. https://www.apta.org/uploadedFiles/APTAorg/Practice_and_Patient_Care/PR_and Marketing/Market to Professionals/TodaysPhysicalTherapist.pdf

APTA. (2018). Beyond opioids: How physical therapy can transform pain management to improve health.

https://www.apta.org/uploadedFiles/APTAorg/Advocacy/Federal/Legislative_Issues/ Opioid/APTAOpioidWhitePaper.pdf

APTA. (2019). Vision statement for the physical therapy profession and guiding principles to achieve the vision. http://www.apta.org/Vision/

APTA. (2020). Role of a physical therapist. http://www.apta.org/PTCareers/RoleofaPT

American Speech-Language Hearing Association [ASHA]. (2020). About speechlanguage pathology. https://www.asha.org/Students/Speech-Language-Pathologists/

ASHA. (2019). Standards for accreditation of graduate education programs in audiology and speech-language pathology. https://caa.asha.org/wpcontent/uploads/Accreditation-Standards-Documentation-Guidance.pdf

American Society of Addiction Medicine [ASAM]. (2020). What is the ASAM criteria? https://www.asam.org/resources/the-asam-criteria/about

Baker, D. W. (2017). The joint commission's pain standards: Origins and evolution. Oakbrook Terrace. https://cergm.carter-brothers.com/wpcontent/uploads/2019/03/2019-03-07-Joint-Commission-on-Pain-2017.pdf

Black, W. R., \& Kashikar-Zuck, S. (2017). Exercise interventions for juvenile fibromyalgia: Current state and recent advancements. Pain Management, 7(3), 143148. https://doi.org/10.2217/pmt-2016-0066

Bridges, D., Davidson, R., Odegard, P., Maki, I., \& Tomkowiak, J. (2011). Interprofessional collaboration: Three best practice models of interprofessional education. Medical Education Online, 16(1), 6035. https://doi.org/10.3402/meo.v16i0.6035

Brooks, M., Holm, S., Thomas, S., \& Rich, A. (2017). Addressing opioid misuse and abuse through interprofessional engagement and education. The Internet Journal of Allied Health Sciences and Practice, 16(1), 1-11.

Centers for Disease Control and Prevention. (2018). Drug overdose deaths. https://www.cdc.gov/drugoverdose/data/statedeaths.html

Chikwanha, T. M. (2019). Exploring factors shaping family involvement in promoting the participation of adults with substance use disorders in meaningful 
occupations [Doctoral dissertation, Stellenbosch: Stellenbosch University]. http://scholar.sun.ac.za/handle/10019.1/105954

Clark, A. (2014). Legislative: Responding to the fatal opioid overdose epidemic: A call to nurses. The Online Journal of Issues in Nursing, 19(3).

http://ojin.nursingworld.org/MainMenuCategories/ANAMarketplace/ANAPeriodical s/OJIN/Columns/Legislative/Responding-to-Fatal-Opioid-Overdose-Epidemic.html

Cohen, E. M., Morley-Fletcher, A., Mehta, D. H., \& Lee, Y. C. (2017). A systematic review of psychosocial therapies for children with rheumatic diseases. Pediatric Rheumatology, 15, 1-9. https://doi.org/10.1186/s12969-016-0133-1

Commission on Accreditation in Physical Therapy Education. (2016). 2016 CAPTE accreditation handbook. http://www.capteonline.org/AccreditationHandbook/

Compton, W., Jones, C., \& Baldwin, G. (2016). Relationship between nonmedical prescription- opioid use and heroin use. New England Journal of Medicine, 374, 154163. https://doi.org/10.1056/nejmra1508490

Costa, D. (2016). Occupational therapy's role in countering opioid addiction. OT Practice, 22(1), 12-16.

Council on Academic Accreditation. (2019). Standard for accreditation. https://caa.asha.org/wp-content/uploads/Accreditation-Standards-DocumentationGuidance.pdf

Council on Social Work Education. (2015). Educational policy and accreditation standards. https://cswe.org/getattachment/Accreditation/Standards-and-Policies/2015EPAS/2015EPASandGlossary.pdf.aspx

Dahn, J. (2016). The nurse's role in the opioid crisis. Arizona Nurse, 6(4), 1-8.

DeBoth, K., Stoddard-Dare, P., Bruce, S., \& Neiderrider, J. (2019). An interprofessional case study competition addressing community healthcare needs and the opioid crisis, Journal of Interprofessional Education \& Practice, 15, 114-118. https://doi.org/10.1016/j.xjep.2019.03.007

Dowell, D., Haegerich, T. M., \& Chou, R. (2016). CDC guideline for prescribing opioids for chronic pain - United States. Morbidity and Mortality Weekly Report, 65(RR-1), 1-49. https://doi.org/10.15585/mmwr.rr6501e1

Dysvik, E., Kvaløy, J. T., Stokkeland, R., \& Natvig, G. K. (2010). The effectiveness of a multidisciplinary pain management programme managing chronic pain on pain perceptions, health-related quality of life and stages of change--A non-randomized controlled study. International Journal of Nursing Studies, 47(7), 826-835. https://doi.org/10.1016/j.ijnurstu.2009.12.001

Eccleston, C., Morley, S. J., \& Williams, A. C. (2013). Psychological approaches to chronic pain management: Evidence and challenges. British Journal of Anaesthesia, 111(1), 59-63. https://doi.org/10.1093/bja/aet207 
Edlund, M. J., Martin, B. C., Russo, J. E., DeVries, A., Braden, J. B., \& Sullivan, M. D. (2014). The role of opioid prescription in incident opioid abuse and dependence among individuals with chronic noncancer pain: The role of opioid prescription. The Clinical Journal of Pain, 30(7), 557-564. https://doi.org/10.1097/ajp.0000000000000021

Evans, J. R., Benore, E., \& Banez, G. A. (2016). The cost-effectiveness of intensive interdisciplinary pediatric chronic pain rehabilitation. Journal of Pediatric Psychology, 41(8), 849-856. https://doi.org/10.1093/jpepsy/jsv100

Fernández-de-Las Peñas C., Ortega-Santiago R., de la Llave-Rincón A., Martínez-Perez, A., Fahandezh-Saddi Díaz, H., Martínez-Martín, J., \& Pareja, J. A. (2015). Manual Physical therapy versus surgery for carpal tunnel syndrome: A randomized parallelgroup trial. Journal of Pain, 16(11), 1087-1194. https://doi.org/10.1016/j.jpain.2015.07.012

Fields, H. (2011). The doctor's dilemma: Opiate analgesics and chronic pain. Neuron, 69(4), 591-594. https://doi.org/10.1016/j.neuron.2011.02.001

Finan, P., Goodin, B., \& Smith, M. T. (2013). The association of sleep and pain: An update and a path forward. Journal of Pain, 14(2), 1539-1552. https://doi.org/10.1016/j.jpain.2013.08.007

Fisher, E., Heathcote, L., Palermo, T. M., de C Williams, A. C., Lau, J., \& Eccleston, C. (2014). Systematic review and meta-analysis of psychological therapies for children with chronic pain. Journal of Pediatric Psychology, 39(8), 763-782. https://doi.org/10.1093/jpepsy/jsu008

Fusco, N, Maerten-Rivera, J., Doloresco, F., \& Ohtake, P. (2019). Improving pharmacy students' attitudes toward collaborative practice through a large-scale interprofessional forum targeting opioid dependence. American Journal of Pharmaceutical Education, 83(6), 1226-1232.

Hager, K., Blue, H., Zhang, L., \& Palombi, L. (2018). Opioids: Cultivating interprofessional collaboration to find solutions to public health problems, Journal of Interprofessional Care, 5, 1-5. https://doi.org/10.1080/13561820.2018.1516634

Harding, K., Day, M. \& Ehde, D. (2018). Mental and physical health correlates of pain treatment utilization among veterans with chronic pain: A cross-sectional study. Military Medicine, 184(4), e127-e134. https://doi.org/10.1093/milmed/usy235

Hawk, K. F., Vaca, F. E., \& D'Onofrio, G. (2015). Reducing fatal opioid overdose: Prevention, treatment and harm reduction strategies. The Yale journal of biology and medicine, 88(3), 235-245.

Hesse, T., Holmes, L. G., Kennedy-Overfelt, V., Kerr, L. M., \& Giles, L. L. (2015). Mindfulness-Based Intervention for Adolescents with Recurrent Headaches: A Pilot Feasibility Study. Evidence - Based Complementary and Alternative Medicine, 2015(508958), 1-9. https://doi.org/10.1155/2015/508958 
Holth, H., Werpen, H., Zwart, J., \& Hagen, K. (2008). Physical inactivity is associated with chronic musculoskeletal complaints 11 years later: Results from the NordTrøndelag Health Study. BMC Musculoskeletal Disorders, 9(159), 1-7. https://doi.org/10.1186/1471-2474-9-159

Jedlicka, J. S., Haskins, A. M., \& Stube, J. E. (2011). Occupational therapy in clientcentered pain management. In N. Vadivelu, R. D. Urman, \& R. L. Hines (Eds.) Essentials of Pain Management (pp. 317-336). Springer. https://doi.org/10.1007/978$\underline{0-387-87579-8 \quad 15}$

Jones, C., Campopiano, M., Baldwin, G., \& McCance-Katz, E. (2015). National and state treatment need and capacity for opioid agonist medication- assisted treatment. American Journal of Public Health, 105(8), e55-63. https://doi.org/10.2105/AJPH.2015.302664

Kaufman, R. R. (2019). Addressing opioid epidemic through interprofessional education and communication is key. Journal of Addictions Nursing, 30(2), 77. https://doi.org/10.1097/jan.0000000000000284

Korthuis, P., McCarty, D., Weimer, M., Bougatsos, C., Blazina, I., Zakher, B., Grusing, S., Devine, B., \& Chou, R. (2017). Primary care-based models for the treatment of opioid use disorder: A scoping review. Annals of Internal Medicine, 166(4), 268-278. https://doi.org/10.7326/m16-2149

Lagueux, E., Dépelteau, A., \& Masse, J. (2018). Occupational therapy’s unique contribution to chronic pain management: A scoping review. Pain Research and Management, 2018. https://doi.org/10.1155/2018/5378451

Liaison Committee on Medical Education. (2020, February 14). Accreditation standards. http://lcme.org/publications/

McCombie, R. P., \& Stirling, J. L. (2018). Opioid substance abuse among occupational therapy clients. Occupational Therapy in Mental Health, 34(1), 49-60. https://doi.org/10.1080/0164212x.2017.1360827

Messer, A. (2017). Nurses working together to fight the opioid epidemic. Mississippi RN, 79(1), 12-13.

Miller, W.R., \& Rollnick, S. (1991). Motivational interviewing: Preparing people to change addictive behavior. The Guildford Press.

Monteiro, K. Dumenco, L., Collins, S., Bratberg, J., MacDonnell, C., Jacobson, A., Dollase, R., \& George, P. (2017). An interprofessional education workshop to develop health professional student opioid misuse knowledge, attitudes, and skills. Journal of the American Pharmacists Association, 57, S113-S117. https://doi.org/10.1016/j.japh.2016.12.069

National Association of Social Workers. (2017). NASW code of ethics. https://www.socialworkers.org/About/Ethics/Code-of-Ethics/Code-of-Ethics-English 
National Institute on Drug Abuse [NIDA]. (2016). Effective treatments for opioid addiction. https://www.drugabuse.gov/publications/effective-treatments-opioidaddiction/effective-treatments-opioid-addiction

NIDA. (2019). NIDA funding opportunities. https://www.drugabuse.gov/funding/nidafunding-opportunities

Phillips, D. M. (2000). JCAHO pain management standards are unveiled. Joint Commission on Accreditation of Healthcare Organizations. Journal of the American Medical Association, 284(4), 428-9. https://doi.org/10.1001/jama.284.4.423b

Potter, P. A., Perry, A. G., Stockert, P. A., \& Hall, A. M. (2107). Fundamentals of nursing (9th ed.). Elsevier.

Providers Clinical Support System [PCSS]. (2017). Motivational interviewing: Talking with someone struggling with opioid addiction. https://pcssnow.org/resource/motivational-interviewing-talking-with-someonestruggling-with-opioid-addiction/

PCSS. (2020). Home. https://pcssnow.org

Public Health Accreditation Board. (2014). Standards and measures. https://www.phaboard.org/wp-content/uploads/2019/01/PHABSM_WEB_LR1.pdf

Proctor-Williams, K. (2018). The opioid crisis on our caseloads. The ASHA Leader 23 (11), 42-49. https://doi.org/10.1044/leader.ftr1.23112018.42

Ramos, C., Cleman-Cope, L., Samuel-Jakubos, H. Basurto, L. (2018). Evidence-based interventions for adolescent opioid use disorder. Urban Institute. https://www.urban.org/sites/default/files/publication/98990/evidencebased_interventions_for_adolescent_opioid_use_disorder.pdf

Rojo-Mota, G., Pedrero-Pérez, E. J., \& Huertas-Hoyas, E. (2017). Systematic review of occupational therapy in the treatment of addiction: Models, practice, and qualitative and quantitative research. American Journal of Occupational Therapy, 71(5), 1-11. https://doi.org/10.5014/ajot.2017.022061

Rowe, N. C., \& Breeden, K. L. (2018). Opioid guidelines and their implications for occupational therapy. OT Practice, 23(15), 1-10. https://www.aota.org/ /media/Corporate/Files/Publications/CE-Articles/CE-ArticleAugust-2018.pdf

Schwindt, R., McNelis, A., Agley, J., Hudmon, K., Lay, K., \& Bentley, M. (2017). Assessing perceptions of interprofessional education and collaboration among graduate health professions students using the Interprofessional Collaborative Competency Attainment Survey (ICCAS). Journal of Interprofessional Education and Practice, 8, 23-27. https://doi.org/10.1016/j.xjep.2017.05.005

Simons, L., Logan, D., Chastain, L., \& Cerullo, M. (2010). Engagement in multidisciplinary interventions for pediatric chronic pain: parental expectations, 
barriers, and child outcomes. The Clinical Journal of Pain, 26(4), 291-299.

https://doi.org/10.1097/AJP.0b013e3181cf59fb

Society, F. (2019). Getting started with mindfulness.

https://www.mindful.org/meditation/mindfulness-getting-

started/?gclid=Cj0KCQjwitPnBRCQARIsAA5n8415xwj7XnrrOw\%20QCndoVDWL

zadAg6c5LC-aThFGKrRJRvx40o0J94aAnglEALw wc

Substance Abuse and Mental Health Services Administration [SAMHSA]. (2018).

Medication and counseling treatment. https://www.samhsa.gov/medication-assistedtreatment/treatment

Stoddard-Dare, P. (2020). How to use drughelp.care [Video].

https://drughelp.care/static/media/Drughelp care How To Video v1 small.ca5229a

9.mp4

Sytsma, T., Haller, E., Youdas, J., Krause, D. K., Hellyer, N. J., Pawlina, W., \& Lachman, N. (2015). Long-term effect of a short interprofessional education interaction between medical and physical therapy students. Anatomical Sciences Education, 8(4), 317-323. https://doi.org/10.1002/ase.1546

VanAllen, A. (2018, November 16). Cleveland State University Created an APP to Help People Find Open Drug Treatment Beds Instantly. News Channel 5 Cleveland, https://www.news5cleveland.com/news/local-news/cleveland-metro/cleveland-stateuniversity-created-an-app-to-help-people-find-open-drug-treatment-bedsinstantly?fbclid=IwAR2YJHsiF8fmRhup-BLPB5LG86qoXN6W8dV2IvHlsfiEusLtwdjBU2FNMo

Van Zee, A. (2009). The promotion and marketing of oxycontin: commercial triumph, public health tragedy. American Journal of Public Health, 99(2), 221-227. https://doi.org/10.2105/ajph.2007.131714

Wagner, K., Liu, L., Davidson, P., Cuevas-Mota, J., Armenta, R., \& Garfein, R. (2015). Association between non-fatal opioid overdose and encounters with healthcare and criminal justice systems: Identifying opportunities for intervention. Drug and Alcohol Dependence, 153, 215-220. https://doi.org/10.1016/j.drugalcdep.2015.05.026

Wamsley, M., Staves, J., Kroon, L., Topp, K., Hossaini, M., Newlin, B., Lindsay, C., \& O'Brien, B. (2012). The impact of an interprofessional standardized patient exercise on attitudes toward working in interprofessional teams. Journal of Interprofessional Care, 26(1), 28-35. https://doi.org/10.3109/13561820.2011.628425

Wasmuth, S., Crabtree, J. L., \& Scott, P. J. (2014). Exploring addiction-asoccupation. British Journal of Occupational Therapy, 77(12), 605-613. https://doi.org/10.4276/030802214x14176260335264

Waszak, D. L., Mitchell, A. M., Ren, D., \& Fennimore, L. A. (2018). A quality improvement project to improve education provided by nurses to ED patients prescribed opioid analgesics at discharge. Journal of Emergency Nursing, 44(4), 336334. https://doi.org/10.1016/j.jen.2017.09.010 
World Health Organization. (2010). Framework for action on interprofessional education and collaborative practice.

https://apps.who.int/iris/bitstream/handle/10665/70185/WHO_HRH_HPN_10.3_eng. pdf;jsessio

Author note: Address correspondence to-Patricia Stoddard Dare, School of Social Work, Cleveland State Univeristy, 2121 Euclid Avenue, RT 1431, Cleveland OH 44115. Email: p.stoddarddare@csuohio.edu 